\title{
Laboreal
}

Volume $7 \mathrm{~N}^{\circ} 1$ | 2011

Psicodinâmica e psicopatologia do trabalho

\section{Uma luta pelo reconhecimento do trabalho contra a política de redução de pessoal}

Una lucha por el reconocimiento del trabajo contra la política de recorte de personal

Une lutte pour la reconnaissance au travail et contre la politique de réduction du nombre des travailleurs

A struggle for the recognition of work against workforce reduction policy

\section{Leda Leal Ferreira}

\section{OpenEdition}

\section{Journals}

\section{Edição electrónica}

URL: http://journals.openedition.org/laboreal/8042

DOI: $10.4000 /$ laboreal.8042

ISSN: 1646-5237

\section{Editora}

Universidade do Porto

\section{Refêrencia eletrónica}

Leda Leal Ferreira, «Uma luta pelo reconhecimento do trabalho contra a política de redução de pessoal », Laboreal [Online], Volume $7 \mathrm{~N}^{0} 1$ | 2011, posto online no dia 01 julho 2011, consultado o 10 outubro 2019. URL : http://journals.openedition.org/laboreal/8042; DOI : 10.4000/laboreal.8042

Este documento foi criado de forma automática no dia 10 outubro 2019.

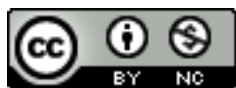

Laboreal está licenciado com uma Licença Creative Commons - Atribuição-NãoComercial 4.0 Internacional. 


\section{Uma luta pelo reconhecimento do trabalho contra a política de redução de pessoal}

Una lucha por el reconocimiento del trabajo contra la politica de recorte de personal

Une lutte pour la reconnaissance au travail et contre la politique de réduction du nombre des travailleurs

A struggle for the recognition of work against workforce reduction policy

Leda Leal Ferreira

\section{Introdução}

1 Este texto pretende revisitar um estudo realizado no início da década de 1990 numa refinaria de petróleo, no Brasil (Ferreira, Iguti \& Jackson, 1991). Seu motivo foi a resistência de operadores de uma unidade de processo [ $\left.{ }^{1}\right]$ da refinaria à política de redução de pessoal que a empresa começava a aplicar e foi o primeiro de uma série de outros que se desenvolveram por mais de uma década, sempre sobre o mesmo assunto e na área do petróleo [2] e dos quais participei, com diferentes status (Ferreira, Iguti, Donatelli, Duarte \& Bussacos, 1997 ; Ferreira, Iguti \& Bussacos, 1998, 1999, 2000a e 2000b). Sem canais de negociação com a empresa, os operadores não hesitaram em explicitar a sua posição através da imprensa local, onde alertavam a população vizinha sobre os riscos que corria pela diminuição de pessoal. Com isto, sensibilizaram autoridades, entre elas o Ministério Público [3], que nos solicitou um estudo para dimensionamento do número de operadores através do estudo de "tempos e movimentos".

2 Não conhecíamos refinarias e nunca tínhamos realizado nenhum dimensionamento de pessoal. Além do mais, o método de "tempos e movimentos" não fazia parte (e ainda não faz), de nossas ferramentas de trabalho. Mesmo assim o assunto nos interessou e, 
inspirados na Análise Ergonômica do Trabalho [4], propusemos ao Ministério Público proceder a uma análise do trabalho destes operadores e a uma avaliação de sua carga de trabalho. Assim, dizíamos nós, poderíamos oferecer subsídios para a definição do número de pessoas necessárias para a operação. Nossos termos foram aceites e o estudo se iniciou. Depois de sete meses, nos quais fizemos várias observações sobre o trabalho realizado (em diferentes horários, realizando diferentes tarefas e em diferentes situações), além de analisar vários tipos de materiais (documentos técnicos sobre o funcionamento da unidade, documentos sobre a segurança da unidade, documentos administrativos sobre a alocação de pessoal e sobre o perfil dos operadores) e de entrevistar várias pessoas, de vários níveis hierárquicos, concluímos que a única justificativa da empresa para a redução do seu efetivo operacional era a diminuição de custos : embora ela alegasse melhorias tecnológicas, não foi o que observamos. Tendo em vista a natureza perigosa e complexa do trabalho realizado, nos pareceu injustificável diminuir o número de operadores, uma vez que isto significava sobrecarga de trabalho e consequente aumento do risco.

3 Nossa conclusão ensejou uma ação civil pública que culminou na condenação da empresa em aumentar o número de seus operadores [5]. No entanto, a mesma recorreu da sentença e foi apenas depois de muitas lutas em várias unidades operacionais da empresa por todo o país que, com a mudança do governo federal e da direção da empresa, em 2003, a política de redução de efetivos começou a mudar, com a realização de concursos públicos para a contratação de novos operadores [ [ $]$.

4 Neste texto, meu propósito é tentar interpretar o conflito entre operadores e empresa como uma espécie de luta pelo reconhecimento do seu trabalho. Como se sabe, o reconhecimento do trabalho é um conceito fundamental da psicodinâmica do trabalho, tema deste número especial da Laboreal. Acredito que, o fazendo, não estou a diminuir a importância política do conflito nem seu caráter de luta contra a intensificação do trabalho (Ferreira, 2000) ; estou apenas procurando iluminar uma de suas facetas.

Na primeira parte, vou descrever alguns aspectos do desenvolvimento do estudo para, posteriormente, tentar interpretar alguns de seus resultados à luz do conceito de reconhecimento do trabalho, conforme o mesmo está sendo desenvolvido por Dejours (1993, 2007 e 2009).

\section{Primeiras impressões em uma refinaria}

Era a primeira vez que eu estava entrando numa refinaria de petróleo. Do primeiro contato com a direção me lembro apenas da tentativa do Superintendente de desqualificar o assunto, minimizando sua importância e atribuindo-o apenas a "reivindicações sindicais de caráter político". Foi nesta ocasião que, também pela primeira vez, ouvi a expressão "enxugamento de pessoal" : a unidade (e a refinaria) estaria com um número de operadores muito superior ao das refinarias norteamericanas, tidas como exemplo de eficiência e modernização, porque vinha trabalhando com mais operadores do que necessário. A redução, portanto, era necessária para se "cortar gorduras", uma vez que "como já estava demonstrado internacionalmente, segurança era sinônimo de efetivos reduzidos". Com estas declarações, o caráter político do conflito ficava imediatamente visível. Após apresentar minhas credenciais, informei que o estudo seria realizado por uma equipe 
de técnicos [7], sob minha coordenação e que passaríamos uma boa temporada ali, necessitando ter acesso a alguns documentos e aos locais de trabalho.

7 Em seguida, fomos conhecer a "unidade" que era motivo da nossa presença. Para chegar até lá precisamos de um carro porque a distância era grande. No caminho, a impressão era a de um local deserto : só víamos tubulações e, de quando em quando, aglomerados de equipamentos gigantescos : tanques, esferas, torres, chaminés. Aqui e ali, nuvens de fumaças brancas pareciam sair do solo e chamas tremulavam no alto de imensas estruturas metálicas.

8 Ao chegar à unidade, logo nos explicaram que ela tinha dois espaços: a "sala de controle" e o "campo" ou a "área". A primeira ficava numa construção de alvenaria com vários compartimentos (como vestiários, refeitório e banheiros). Da sua grande janela vidrada, podíamos ver grande parte dos equipamentos do campo, que ocupavam uma extensa área de mais de 70 mil metros quadrados. A sala de controle assim se chamava porque era de lá que se controlava o processo, isto é, o conjunto das transformações pelas quais as matérias primas passavam para a fabricação dos produtos derivados de petróleo que a unidade produzia e que ocorriam "no campo", dentro de numerosos, volumosos e variados equipamentos: um conjunto de torres; vasos e bombas interligados entre si e a um sistema de tochas ; trocadores de calor ; um sistema de resfriamento; um sistema de tratamento de água; fornos e um parque de armazenamento de produtos. A sala era ocupada por um grande painel analógico [8]. Centenas de informações, referentes a registros de temperaturas, pressões, volumes e fluxos de várias partes do que acontecia com os produtos dentro dos equipamentos lá fora, estavam ali. Também estavam ali alguns dispositivos a partir dos quais se podia interferir à distância no processo, fechando ou abrindo algumas válvulas ou acionando alguns comandos ; e uma grande quantidade de alarmes - visuais e sonoros - para avisar a todos sobre o que não estava dando certo. À primeira impressão, tudo parecia extremamente moderno e altamente automatizado.

9 A sala nunca ficava vazia. Havia sempre pelo menos três operadores ali [ $\left.{ }^{[}\right]$e os demais, quando iam ou voltavam do campo, sempre passavam por ela, assim como o faziam operadores de outras unidades, da manutenção e a hierarquia do setor. Seu funcionamento era contínuo. Dia e noite, durante todos os dias do ano, operadores se revezavam no serviço porque a unidade não podia parar de produzir $\left[{ }^{[0]}\right.$.

\section{Compreender o processo e o trabalho dos operadores}

10 Nosso primeiro contato com os operadores, quando chegamos à sala de controle, foi lhes explicar quem éramos. Dissemos que estávamos ali por solicitação do Ministério Público para fazer um estudo e que deveríamos fazer uma série de observações sobre o trabalho deles, acompanhando-os em várias situações, em diversos dias e em diferentes horários e turnos e conversando com eles, além de ter acesso a documentos de trabalho. A reação deles foi um misto de curiosidade e descrença, de incômodo e alívio. Afinal, se por um lado o estudo lhes interessava, por outro nossa presença realimentava uma situação extremamente desconfortável : o conflito com a direção. Além do mais, éramos totalmente desconhecidos: entenderíamos realmente o problema? o que faríamos ali? Os resultados de nosso trabalho iriam ajudá-los ou, ao contrário, prejudicá-los ? [11]. E nossa presença, como toda presença externa em uma situação de trabalho, poderia atrapalhar sua atividade. Assim, foi com uma natural desconfiança 
que os operadores nos receberam. Foi só na medida em que eles começaram a nos conhecer melhor que foram escasseando os "testes" que nos fizeram passar, levandonos para longas e cansativas caminhadas no campo, forçando-nos a subir e descer escadas que nos levavam a alturas elevadas, verificando nossas reações ao sermos obrigados a vestir alguns pesados e desconfortáveis equipamentos de proteção individual, testando nossa compreensão durante as explicações que nos davam em resposta às nossas questões sobre o funcionamento de um equipamento, o significado de uma ação, o sentido de uma palavra, em nossas tentativas de compreender o processo.

11 Para nós, compreender o processo era fundamental para compreender a função dos operadores no seu controle, isto é, o trabalho deles. Por isso, além de observá-los trabalhando e falar com eles, estudamos uma série de documentos internos e externos da refinaria. Tudo indicava o seu risco e a sua complexidade. Risco pela natureza e a grande quantidade de produtos utilizados, explosivos, inflamáveis e/ou tóxicos, submetidos a condições anormais de temperatura e pressão. Complexidade pela grande quantidade de variáveis que interagiam, adquirindo, a cada momento, uma nova configuração e representando assim "acontecimentos" diferentes e muitas vezes, imprevisíveis. Compreendemos que o trabalho dos operadores consistia em controlar o risco para produzir o produto final. Ou seja, controlar o risco não era uma tarefa secundária; era o pano de fundo de seu trabalho e estava, explícita ou implicitamente, permeando todas as atividades.

12 Além disso, a análise nos ensinou que o controle do processo e do risco era um trabalho coletivo. Por diversas vezes, pensei em um jogo de futebol para explicar o trabalho dos operadores. Em uma unidade de processo, como numa partida de futebol, o resultado do trabalho é fruto não de uma pessoa, mas de uma equipe na qual cada um tem uma função diferente, mas complementar, à dos outros e na qual ocorrem vários tipos de interações, sequenciais ou simultâneas.

13 Na unidade em questão, os operadores (seis por turno, equivalentes ao "número mínimo" [12]) se alternavam entre os que ficavam dentro e fora da sala de controle, segundo uma tabela de rodízio que eles próprios tinham elaborado. Quem ficava na sala era responsável pela vigilância dos painéis de controle. Pelo menos duas pessoas o faziam : uma era responsável por uma parte do processo e a outra, pela outra. Quem ia para a área, deveria seguir uma "rotina", que incluía várias operações como o exame dos equipamentos, a execução ou o acompanhamento de uma manobra, a leitura de alguns indicadores, etc. $\mathrm{O}$ importante, porém, era que estes dois tipos de atividades se complementassem de modo que a unidade funcionasse e produzisse normalmente. Por isso, era importante que cada um conhecesse bem o que deveria fazer e, principalmente, acompanhasse o que estava acontecendo no processo. Toda vez que os operadores de campo voltavam da área e entravam na sala de controle, davam uma olhada no painel de onde tiravam muitas informações importantes. Para conseguir fazê-lo, era importante que tivessem um bom conhecimento da unidade e de seu funcionamento. 0 rodízio entre "campo" e "painel" era um mecanismo para garantir esse conhecimento. Cada instrumento no painel correspondia a uma parte do processo real que acontecia lá fora e era preciso que o operador fizesse essa correspondência, visualizando-a "na sua imaginação", como nos explicaram. "Apertar um botão para abrir ou fechar uma válvula todo mundo sabe. 0 problema é apertar o botão da válvula certa no momento certo" diziam e "saber todas as implicações" deste ato 
aparentemente tão simples. Esta era uma grande preocupação para eles, pois quanto melhor fosse seu conhecimento geral do processo, melhor poderiam atuar e melhor poderiam controlar o risco. Devido ao elevado grau de complexidade do processo, para bem conhecê-lo os operadores estimavam serem necessários vários anos de prática e de estudos teóricos (um operador nos mostrou todas as anotações que fizera, ao longo de seus vinte anos de trabalho, a respeito dos "alinhamentos" do sistema, isto é, do caminho que os produtos percorriam pelas tubulações, para estudá-los e não esquecêlos).

14 Além disso, o controle do processo exigia um grau de atenção constante. A qualquer momento, podia ocorrer uma variação que exigisse uma providência rápida, quase instantânea, para se evitar uma ocorrência anormal ou até uma catástrofe. Bons operadores eram aqueles que, além de conhecer bem o processo, o sentiam. Eles viam uma fumaça diferente, sentiam um odor estranho, percebiam uma vibração nova, escutavam um barulho peculiar, visualizavam a posição de uma válvula e já sabiam o que estava certo ou errado. Estas informações "corporais" eram tão importantes como os registros formais e a eles eram integradas para que cada um tivesse, continuamente, uma boa representação do que estava acontecendo.

Seu trabalho era um constante resolver problemas. Todas as vezes que algo anormal acontecia (o que era freqüente), era preciso entender suas causas e suas conseqüências para poder atuar bem e no momento certo. Nessas situações, as conversas entre vários operadores se adensavam, sempre em linguagem operacional (levamos vários meses para compreender um pouco melhor esta linguagem). Era a partir desta troca de informações que muitos problemas eram resolvidos, evitando perdas de produtos ou situações perigosas.

\section{Quando o número de operadores diminui}

Retomando a comparação esportiva, podemos dizer que a ausência de uma ou mais pessoas na equipe, além de sobrecarregar as demais, modifica a posição de todos e de cada um. No futebol, um time desfalcado pode até vencer uma partida, mas dificilmente consegue ganhar um campeonato jogando sistematicamente com menos de onze jogadores em cada jogo. Na refinaria, a diminuição do número de operadores estava obrigando a um remanejamento do serviço de cada um e de todos os operadores que restavam para dar conta do trabalho que não era feito por aqueles que não estavam mais lá. Com vários efeitos negativos. Com menos pessoas, as conversas entre os operadores rareavam e eles não podiam mais "perder tempo" com a rotina. Ora uma rotina bem feita era uma condição necessária para se atualizar o grau de conhecimento do estado do processo e dos equipamentos. A sobrecarga de trabalho era visível porque o perigo e a complexidade do processo não permitiam que se deixasse de fazer determinadas operações. Ao mesmo tempo, a impossibilidade de fazer tudo o que se fazia antes, obrigava-os a priorizar o que fazer entre várias coisas importantes, criando situações verdadeiramente conflituosas, psicológica e moralmente.

No entanto, estes problemas pareciam não ser considerados pela hierarquia. A concepção do trabalho dos operadores como sendo perigoso, complexo e coletivo [13] não era compartilhada por ela, que tinha a tendência de considerá-lo bem mais simples. 
18 Não é de se estranhar, portanto, que os trabalhadores se indignassem com algumas manifestações de menosprezo pela sua atividade : um operador nos mostrou um bilhete de um chefe, guardado há anos, que dizia : 'operador não deve pensar'.

\section{Duas concepções diferentes sobre o trabalho dos operadores}

19 "A refinaria ganha quando o operador está parado, mas engenheiro $\left.{ }^{[14}\right]$ detesta ver operador parado". Esta frase reflete bem um dos problemas que logo identificamos : a diferença entre a concepção que a chefia tinha do trabalho dos operadores e a que eles próprios tinham. Por que a refinaria ganharia com o operador parado? Porque isto significaria que o processo estaria andando sem problemas que necessitassem de alguma intervenção deste operador. 0 operador poderia ficar sentado, parado, observando o seu funcionamento através das indicações do painel. No entanto, parado não significa ausente : pelo contrário, significa que o operador, atento ao que está acontecendo, sabe que não tem que atuar naquele momento. E por que o engenheiro detestaria ver operador parado ? Porque acharia que ele estaria ocioso, o que é um dos maiores "pecados" que os trabalhadores podem cometer no mundo do trabalho. Em várias situações, vimos chefias incomodadas com a aparente ociosidade dos operadores quando estavam diante dos painéis, como se a única coisa que pudesse comprovar o seu trabalho fosse a sua movimentação física.

De um modo geral, as direções creditam à tecnologia um poder que apenas os operadores possuem : a capacidade de pensar e resolver problemas, inclusive aqueles gerados por falhas na tecnologia. Por isso, muitas vezes, nos disseram que o trabalho dos operadores era só (sic) vigiar o painel do controle, ignorando as limitações na automação da unidade, o caráter complexo e imprevisível do funcionamento do processo e as próprias falhas da tecnologia : observamos inúmeras ocasiões nas quais os operadores, frente a indicações no painel, se perguntavam se elas seriam reais ou apenas fruto de defeitos nos instrumentos de medições, sem contar as possibilidades de paradas de emergência, por exemplo, por falta de energia, que obrigavam os operadores a retomar o processo em "modo manual".

21 Estas diferenças entre as concepções das chefias e a dos operadores sobre o trabalho dos mesmos eram visíveis em vários aspectos, como já mostramos (Ferreira, 1996): enquanto a direção considerava os riscos sob controle desde que as normas de segurança fossem respeitadas, os operadores diziam que os riscos podiam fugir ao controle, mesmo que as normas de segurança fossem respeitadas. Enquanto a direção considerava o funcionamento do dispositivo tecnológico normalizado e com poucas alterações, os operadores diziam o contrário. Enquanto para a direção os operadores tinham poucas tarefas, todas relativamente simples, os operadores afirmavam que tinham muitas tarefas diferentes, algumas de alta complexidade. Enquanto para a direção a alocação das tarefas entre os operadores era bem delimitada, para os próprios operadores esta delimitação nunca era tão nítida. Enquanto, para a direção, os modos operatórios eram fixos e repetitivos, para os operadores eles eram variáveis e heurísticos porque deveriam corresponder às situações reais do sistema. Enquanto para a chefia havia um predomínio de tarefas de simples vigilância, para os operadores o importante eram as tarefas de planejamento e de pronta intervenção. A direção também não levava em consideração as variações do estado dos operadores em função 
das mudanças de horário devidas ao sistema de turnos alternantes; já os operadores, sabiam como seu estado era alterado física e mentalmente em função das trocas de horários. Para a direção a gestão da unidade deveria ser baseada na hierarquia, com valorização do desempenho individual ; para os operadores, a gestão do trabalho na unidade era um processo coletivo e, portanto, a experiência prática coletiva deveria ser valorizada. Enfim, se para a direção o trabalho da equipe era considerado o "somatório" de trabalhos individuais, para os operadores o trabalho da equipe era o resultado de uma "integral" dos trabalhos individuais. Dizendo em outras palavras, para as chefias o trabalho dos operadores era um problema; para os operadores, a solução dos problemas.

Como sintetizou mais tarde um operador experiente (Cequinel, 2003), na sua concepção de trabalho, as chefias confundiam o real com o ideal, o que era com o que gostariam que fosse, e, com este comportamento, desvalorizavam e simplificavam o trabalho dos operadores, fornecendo argumentos técnicos ao processo político de redução de efetivos ou downsizing.

\section{A política de redução de pessoal}

23 Na linguagem empresarial, a redução do número de trabalhadores é expressa como "enxugamento de pessoal" ou "corte de gorduras" [15]. Trata-se da versão brasileira do downsizing norte-americano ou do dégraissage francês, uma forma eufêmica de falar sobre o corte de empregos, como dizia Wacquant :

Le verbe to downsize est un terme technique qui provient de l'industrie automobile où Il designe la réduction de la taille des véhicules. C'est en1982 que s'amorce son application aux employés plutôt qu'aux produits d'une firme. Depuis, les directeurs des ressources humaines ont innové un vaste lexique visant "à "adoucir" voire à masquer sémiotiquement les suppressions d'emplois. Dans l'Amérique d'aujourd'hui, notamment au sein des grandes compagnies, un salarié n'est point licencié, limogé ou mis à la porte, et encore moins viré; il est "séparé", "désélectionné" ou "désembauché", "transitionné" ou "réduit", "non realloué" ou "déprogrammé”, "délogé" ou bien encore "non-renouvelé" Quant à l'entreprise, elle se contente de procéder à un "recentrage du mix des qualifications", à une "correction du déséquilibre de main-d'oeuvre" ou encore à une "élimination des redondances". Maints autres vocables diffcilement traduisibles, tels decruited, excessed, ou surplussed, expriment bien cette idée que les employés sont devenus une charge excédentaire, un poids mort, un fardeau inutile, bref une tare dont la firme a le droit mais aussi le devoir de se délester prestement. (Wacquant,1996, p. 70) [16].

Considerar trabalhadores como "gordura" a ser cortada é extremamente pejorativo e dá bem a idéia do caráter de desvalorização do trabalhador e de seu trabalho. Presenciamos várias manifestações desta desvalorização, relacionadas a diferentes aspectos : ao tipo de conhecimento dos operadores ("não sabem nem fazer uma média ponderada") ; à natureza de seu trabalho ("só têm que vigiar os painéis") ; ao emprego de seu tempo ("ficam ociosos"). Com esta desvalorização, a hierarquia conseguia defender a diminuição do tempo de treinamento para ser operador e pregava a polivalência entre vários setores (Cequinel, 2003). 


\section{Uma reunião de reconhecimento}

Quando o estudo chegou ao fim, quisemos fazer uma reunião $\left.{ }^{[17}\right]$ para apresentá-lo aos operadores de modo que os mesmos conhecessem o nosso trabalho e verificassem se não tínhamos nos enganado em algumas terminologias técnicas e próprias do petróleo. A reunião deveria ser feita fora do local de trabalho e, por isso, alguns operadores nos propuseram a sede de um clube local. Lá chegando, no dia marcado, encontramos todos os operadores da unidade, com exceção dos que estavam naquele momento trabalhando na refinaria, o que era, no mínimo, uma demonstração de interesse pelo nosso trabalho.

Primeiro, lhes explicamos em linhas gerais nossas conclusões e o propósito da reunião. Eles imediatamente se organizaram em três grupos (cada grupo acompanhando um de nós, os três pesquisadores) e verificaram todas as nossas dúvidas técnicas, corrigindo alguns pequenos erros que havíamos cometido. Compreenderam, de imediato, alguns esquemas gráficos que tínhamos feito para ilustrar seu trabalho, como os que representavam os longos percursos que faziam durante as rotinas de trabalho, caminhando dentro da unidade, e imediatamente descobriram algumas incoerências dentro deles que nós, prontamente, corrigimos. Quando viram um esquema onde representávamos, num gráfico, uma comparação entre o que a empresa considerava ser o seu trabalho e o que eles efetivamente faziam, que mostrava uma grande diferença (isto é, que eles faziam muito mais coisas e coisas muito mais variadas do que as chefias previam), sua satisfação foi visível : finalmente alguém havia compreendido toda a complexidade e o perigo do trabalho que realizavam. Alguns chegaram mesmo a expressar o alívio que sentiam por ver que o que estavam tentando demonstrar quando denunciavam a diminuição de efetivos não era sinal de covardia ou de falta de vontade de trabalhar: pelo contrário, demonstrava um sentimento de responsabilidade profissional com a produção e segurança e de indignação contra decisões empresariais baseadas apenas em motivos econômicos. Seu trabalho tinha sido reconhecido por nós e, mais importante, este reconhecimento iria se tornar público.

\section{0 reconhecimento do trabalho na psicodinâmica do trabalho}

O conceito de reconhecimento do trabalho tem sido desenvolvido por Christophe Dejours desde, pelo menos, 1993, quando foi publicado um addendum teórico chamado “ Da psicopatologia do trabalho à psicodinâmica do trabalho" na segunda edição ampliada de seu primeiro livro, Travail usure mentale, essai de psychopathologie du travail, de 1980 (traduzido no Brasil, em 1987, como A loucura do trabalho). Foi nesse momento que o trabalho de Dejours deu uma importante guinada: ao invés da psicopatologia, o que passou a ser o foco das suas preocupações foi a normalidade psíquica: como era possível permanecer saudável apesar das graves dificuldades encontradas para se realizar o trabalho? [18] Se a psicopatologia do trabalho era definida como "o sofrimento psíquico resultante da confrontação dos homens à organização do trabalho", as preocupações da nova disciplina eram ampliadas no sentido de fazer uma "análise psicodinâmica dos processos intersubjetivos mobilizados pelas situações de trabalho" (Dejours, 1993, p. 207, tradução livre). Se o trabalho podia ser fonte de 
sofrimento e de distúrbios mentais, ele também podia ser fonte de prazer e de realização pessoal.

Foi nesse contexto que o reconhecimento do trabalho apareceu como conceito fundamental. Era a partir dele que o sofrimento do trabalho poderia ser, de certo modo, não só neutralizado como até transformado em prazer no trabalho. A explicação dada era, mais ou menos e resumidamente, a seguinte: no curso dos enfrentamentos das dificuldades inerentes à realidade do trabalho, os sujeitos se esforçam, isto é, mobilizam suas capacidades físicas, suas inteligências, habilidades e disposições, suas capacidades de relacionamento, suas subjetividades, enfim, para conseguirem um bom resultado. "A mobilização subjetiva é muito forte na maioria dos sujeitos. Tudo se passa como se o sujeito, confrontado à organização do trabalho, não pudesse evitar a mobilização dos recursos de sua inteligência e de sua personalidade" (Dejours,1993, p. 225, tradução livre).

Se estes esforços forem reconhecidos, todo o sofrimento que causaram pode ser, de certa forma, neutralizado e os sujeitos podem experimentar até prazer. Por outro lado, se estes esforços não forem reconhecidos, o sofrimento que causaram é apenas sofrimento, sem sentido, e pode levar a descompensações psíquicas. Haveria, portanto, no trabalho, uma dinâmica entre contribuição e retribuição :

Na contrapartida da contribuição que dá à organização do trabalho, o sujeito espera uma retribuição e, às vezes até, ele só espera que suas iniciativas e seu desejo de contribuir e de não ser apenas um estrito executante, condenado à obediência e à passividade, não sejam sistematicamente sufocados. (Dejours, 1993, p. 225, tradução livre)

Este reconhecimento do qual fala Dejours é um reconhecimento simbólico e, segundo ele, pode adquirir duas formas : a da constatação e a da gratidão, pela "contribuição dos trabalhadores à organização do trabalho". Insiste Dejours que o reconhecimento não é sobre o trabalhador, mas sobre o seu fazer e passa sempre por julgamentos proferidos por outrem : julgamentos de utilidade, como ele os chama, proferidos principalmente pelos superiores hierárquicos e julgamentos de beleza, proferidos pelo pares.

Estes julgamentos têm uma particularidade em comum: se referem ao trabalho feito, isto é, ao fazer e não à pessoa. Mas, em retorno, o reconhecimento da qualidade do trabalho realizado pode se inscrever ao nível da personalidade em termos de ganhos no registro da identidade. Em outras palavras, a retribuição simbólica conferida pelo reconhecimento pode adquirir um sentido em relação a expectativas subjetivas sobre a realização pessoal. (Dejours, 1993, p. 227, tradução livre).

31 É aí que se fecham os "elos intermediários da dinâmica do reconhecimento": o reconhecimento do trabalho é fundamental para a constituição da identidade, que, por sua vez, é fundamental para a saúde mental. "A identidade necessita do olhar dos outros" diz ele. E a "identidade insuficientemente fundada é uma porta aberta à doença mental" (Dejours, 2009, p. 118, tradução livre). o trabalho pode ser um mediador na construção da identidade, fortalecendo psiquicamente o sujeito frente aos riscos de doenças mentais e em dois importantes registros : o da identidade de cada um e o da identidade coletiva. "Com o reconhecimento, são obtidas gratificações preciosas no registro da identidade: de um lado, pertencimento a um coletivo ou a uma comunidade ; de outro, identidade singular" (Dejours, 2009, p. 117, tradução livre). 
Este breve resumo já mostra a importância conferida pela psicodinâmica do trabalho ao reconhecimento do trabalho. Não é demais lembrar que, além da psicodinâmica do trabalho, o tema do reconhecimento, tem sido recentemente motivo de atenção de filósofos e sociólogos de diversas partes do mundo, como Ricoeur (2005 e 2006) e Renault, (2007), na França; Honneth (2007, 2008 e 2009), Voswinkel (2007) e Kocyba (2007), na Alemanha; Fraser (2005 e 2007) nos Estados Unidos e Taylor (1994) no Canadá $\left[{ }^{19}\right]$, para só citar os nomes mais (talvez) conhecidos deste movimento. 0 sugestivo título de um livro editado na França, em 2007, A busca de reconhecimento : novo fenômeno social total (Caillé, 2007), reunindo um conjunto de textos de vários autores sobre, principalmente, a problemática da falta de reconhecimento, mostra como o assunto pode ser analisado sob os mais diferentes pontos de vista.

\section{À guisa de conclusões}

A questão de diminuição de efetivos abordada neste estudo foi apenas o início de um processo de "reestruturação produtiva" pela qual a empresa passou, no afã de diminuir custos e na esteira do que acontecia em todo o mundo nos anos 80 e 90. Nas empresas petrolíferas, em particular, o downsizing foi tão grande que, como disse o ICEM (1998), as empresas petrolíferas começaram a apresentar sinais de "anorexia empresarial", pois os cortes de "gorduras" passaram a atingir seus órgãos vitais[ $\left.{ }^{20}\right]$.

34 No caso brasileiro, alguns grandes acidentes, que culminaram em março de $2001 \mathrm{com}$ o afundamento da plataforma P- 36 que resultou na morte de 11 operadores e na perda total da plataforma, com a comoção nacional que ocasionou, parecem ter sido um sinal definitivo para que a política de redução de pessoal fosse interrompida e, com a mudança de governo, começasse uma política de contratação de pessoal.

No entanto, se durante todo este período os trabalhadores petroleiros não tivessem se manifestado contra esta política, provavelmente seus efeitos teriam sido ainda mais deletérios. De fato, desde o início, os trabalhadores reagiram e, como fizeram no estudo que estamos apresentando, sem canais de negociação com a direção da empresa não hesitaram em levar suas apreensões ao Ministério Público e à Justiça. Só a nossa equipe participou de vários deles, de modo que pudemos nos aprofundar no assunto, conhecer melhor os argumentos de ambos os lados, compreender que a questão da determinação de efetivos era uma questão de negociação e, assim sendo, que caberia a cada uma das partes apresentar seus argumentos e seus números. A insistência da resistência dos sindicatos forçou a empresa a colocar no seu Acordo Coletivo de Trabalho uma cláusula que previa um fórum de discussão sobre a questão dos efetivos e tive a oportunidade de acompanhar um estudo piloto previsto nesta cláusula enquanto assessora do sindicato. Foi uma experiência de três anos que terminou, enfim, com uma vitória (Ferreira, 2003).

Neste longo processo, uma questão sempre me intrigou : por que as empresas, que não se negam a negociar salários, se negam a negociar o número de seus trabalhadores, uma vez que nos dois casos trata-se de uma questão econômica (na medida em que ocorre dentro de limites vigentes e aceitos socialmente) e política (porque depende da correlação de forças entre as partes) e que o custo do trabalho depende não só do nível salarial como do número de empregados ? Uma das explicações para esta discrepância me parece estar na diferença da natureza dos dois tipos de questão : pode-se arbitrar a questão salarial sem discutir o trabalho concreto. Mas para se determinar o número de 
trabalhadores, a discussão sobre o trabalho concreto é imprescindível. É aí que as diferentes concepções sobre o trabalho adquirem todo o seu valor. E é só na medida em que os trabalhadores ousam apresentar e defender o seu trabalho concreto, e confrontá-lo com aquele concebido pela chefia (em geral simplificado e subestimado) que o processo pode progredir, como aconteceu no caso da negociação anteriormente citado.

Mas ainda restam questões, entre elas saber por que os petroleiros resistiram tão bravamente. Parece-me que a noção de perda também é importante: a redução de efetivos representou uma perda na qualidade do trabalho, que sempre foi prezada na empresa e reconhecida nacionalmente ; uma perda na qualificação dos trabalhadores e um baque na imagem de competência dos próprios operadores e na sua reconhecida capacidade de organização e luta.

É por isso que podemos considerar a luta dos petroleiros contra a redução de efetivos como uma luta pelo reconhecimento de seu trabalho, pelo reconhecimento de sua competência e pelo reconhecimento de sua responsabilidade. $O$ que aconteceu foi a feliz coincidência entre a vontade de obter este reconhecimento e as condições de obtê-lo. Estas condições foram dadas pela tradição de participação política e de luta que historicamente marcaram esta categoria no Brasil.

\section{BIBLIOGRAFIA}

Caillé, A. (2007)(Org). La quête de reconnaissance : nouveau phenomène social global. Paris : La Découverte.

Cequinel, P.R. (2003) Considerações sobre efetivos, número mínimo e segurança de pessoas, patrimônio e meio ambiente. (datilografado).

Dejours, C. (1987). A loucura do trabalho. Estudo de psicopatologia do trabalho. Trad. de Ana Isabel Paraguay e Lúcia Leal Ferreira, São Paulo : Cortez-Oboré.

Dejours, C. (1993). De la psychopathologie à la psychodynamique du travail. In Dejours Travail usure mentale, essai de psychopathologie du travail, Nouvelle édition augmentée. Paris : Bayard Dejours, C. (2001). Subjectivité, travail et action. Retirado em 10/10/2010 de http://sites.univprovence.fr/ergolog/pdf/bibliomaster/depours.pdf.

Dejours, C. (2007). Introduction au dossier 'La reconnaissance’. Travailler, 18, 0-16.

Dejours, C. (2009). Travail vivant 2 : travail et émancipation. Paris : Payot.

Federação Única dos Petroleiros (FUP) (2010). Notícias. Retirado em 17/11/2010 de http:// www.fup.org.br/noticias.php?id=425

Ferreira, L. L.(1996). Dois estudos sobre o trabalho dos petroleiros. Produção, vol. 6, noo 1, p. 7-32.

Ferreira, L. L. (2000). Intensificação do trabalho ou "É proibido vacilar". In Francisco Duarte (Org) Ergonomia e projeto na indústria de processo contínuo. Rio de Janeiro : COPPE/UFRJ : Lucerna. 
Ferreira, L. L. (2003) Dez anos de lutas dos sindicatos de petroleiros brasileiros contra a diminuição do número de operadores. $6^{\circ}$ Congreso nacional de estudios del trabajo. Asociación argentina de especialistas en estudios del trabajo. www.aset.org.ar/congresos/6/archivosPDF/.../ 004.pdf

Ferreira, L. L., Iguti, A. M. \& Jackson Filho J.M. (1991). Análise do trabalho dos operadores da unidade de gasolina de aviação da Refinaria Presidente Bernardes de Cubatão da Petrobrás. Estudo solicitado pelo Ministério Público do Estado de São Paulo ao Setor de Ergonomia da Fundacentro. São Paulo : Fundacentro. (datilografado).

Ferreira, L. L. ; Iguti, A. M. ; Donatelli, S. ; Duarte, F. \& Bussacos, M. A. (1997). Correlação entre o número de trabalhadores e as condições de segurança de uma refinaria de petróleo. Estudo solicitado pelo Ministério Público à Fundacentro. São Paulo : Fundacentro (datilografado).

Ferreira, L. L., Iguti, A.M \& Bussacos, M. A. (1998). A diminuição de efetivos em um terminal marítimo de petróleo e o trabalho de seus operadores. Estudo solicitado pelo Ministério Público à Fundacentro. São Paulo : Fundacentro (datilografado)

Ferreira, L. L., Iguti, A. M \& Bussacos, M. A.(1999). Laudo complementar ao estudo "A diminuição de efetivos em um terminal marítimo de petróleo e o trabalho de seus operadores". Estudo solicitado pelo Ministério Público à Fundacentro. São Paulo : Fundacentro (datilografado)

Ferreira, L. L., Iguti, A. M \& Bussacos, M. A. (2000 a). A diminuição do número de operadores em uma refinaria de petróleo : preocupações com a segurança. Estudo solicitado pelo Ministério Público à Fundacentro. São Paulo : Fundacentro (datilografado)

Ferreira, L. L., Iguti, A. M \& Bussacos, M. A. (2000 b). Uma proposta de quadro mínimo de operadores para a RPBC. Estudo solicitado pelo Ministério Público à Fundacentro. São Paulo : Fundacentro (datilografado)

Fraser, N. (2005) Qu'est-ce que la justice sociale? Reconnaissance et redistribution. Paris : La Découverte.

Fraser, N. (2007). Reconhecimento sem ética? Lua Nova, São Paulo, 70 : 101-138 (Artigo originalmente publicado na revista Theory, Culture \& Society, v. 18, p. 21-42, 2001). Trad. de Ana Carolina Freitas Lima Ogando e Mariana Prandini Fraga Assis.

ICEM- Federação Internacional de Sindicatos de Trabalhadores da Química, Energia, Minas e Indústrias Diversas. (1998). Las industrias de la energía en mutación - los sindicatos de la energía se movilizan, http://www.icem.org/eventos/cork/docs-es.html

Honneth, A. (2007) Travail et agir instrumental. Á propos des problèmes catégoriels une théorie critique de la société. Travailler, 18, 17-58.

Honneth, A. (2008) Trabalho e reconhecimento : tentativa de uma redefinição. Civitas, v.8, n.1, 4667

Honneth, A. (2009) Luta por reconhecimento : a gramática moral dos conflitos sociais. $2^{\mathrm{a}}$ ed. São Paulo : Ed. 34.

Kocyba, H. (2007) Reconnaissance, subjectivisation, singularité. Travailler, 18, 103-118.

Renault, E. (2007). Reconnaissance et travail. Travailler, 18:119-135.

Ricoeur, P. (2005). Devenir capable, être reconnu. Texte écrit pour la réception du Kluge Prize, décerné aux États-Unis à Paul Ricoeur em 2005. Retirado em 03/12/2010 de

http://www.diplomatie.gouv.fr/fr/IMG/pdf/Revue_des_revues_200_1152AB.pdf 
Ricoeur, P.(2006). Percurso do reconhecimento. São Paulo: Loyola, 2006.

Taylor, C. (1994) The politics of recognition. In: Gutmann, Amy (Ed.) Multiculturalism: Examining the politics of recognition. Princeton : Princeton University Press.

Tribuna, A, Santos, 21/12/1993.

Voswinkel, S. (2007). L'admiration sans appréciation. Les paradoxes de la double reconnaissance du travail subjectivisé. Travailler, 18, 59-87.

Wacquant, L.J.D. (1996). La généralisation de l'insécurité salariale en Amérique : restructurations d'entreprises et crise de reproduction sociale. Actes de la Recherche en Sciences Sociales, 115, 65-79. Cahier "Les nouvelles formes de domination dans le travail (2)»

\section{NOTAS}

1. Cada "unidade" ou "unidade de processo" da refinaria é uma espécie de fábrica que produz um produto específico derivado do petróleo, como gasolina, diesel, etc.

2. Na década de 1990, a política de pessoal da empresa foi responsável por diminuir o número de seus trabalhadores efetivos de cerca de 60 mil para 33 mil e de terceirizar grande parte de seus serviços.

3. A Constituição Brasileira, desde 1988, deu evidências ao Ministério Público, que passou a ser uma espécie de Ouvidoria da sociedade brasileira, atuando na tutela dos interesses difusos e coletivos. www.mpu.gov.br/navegacao/instituicional/historico. Acesso em 27/10/2010.

4. A Análise Ergonômica do Trabalho ou AET é uma metodologia criada na década de 70, pelo Laboratório de Ergonomia do CNAM em Paris, França, quando seu diretor era Alain Wisner. Representa uma seqüência de etapas para se realizar um estudo ergonômico das quais as mais importantes são a análise da demanda, a análise das condições da empresa e a análise da atividade dos trabalhadores (através de várias técnicas dentre as quais observações detalhadas da mesma são as mais importantes).

5. Em 15 de dezembro de 1993, por sentença do juiz Roberto Maia Filho, fundamentada na ação impetrada pela Promotoria de Meio Ambiente de Cubatão, a empresa foi obrigada a aumentar o número de operadores da unidade em questão e manter um número mínimo de oito operadores por turno (eram seis) acrescidos de um efetivo de mais $30 \%$, totalizando 52 operadores. (A Tribuna, 21/12/1993).

6. Concursos públicos de ingresso para a admissão de pessoal, que estavam suspensos na década de 1990, foram abertos e o efetivo operacional da empresa começou a ser reposto, de modo que em 2010 o efetivo próprio era de cerca de 70 mil trabalhadores. Os sindicatos reconhecem a importância destas novas contratações, mas continuam a denunciar que os trabalhadores estão expostos a cargas de trabalho excessivas (FUP, 2007).

7. A Dra. Aparecida Mari Iguti, médica e doutora em Ergonomia, o engenheiro José Marçal Jackson Filho que, na época, estava em formação em ergonomia e eu mesma.

8. Poucos anos depois, os painéis analógicos foram substituídos por sistemas de controle computadorizados e as salas de controle de cada unidade de processo foram agrupadas em uma única sala, distante do "campo".

9. Indústria capital intensivo, as refinarias de petróleo funcionam com pouquíssimos trabalhadores. Por isso, qualquer alteração no seu número representa uma grande alteração: quando, por exemplo, uma unidade que funcionava com dois operadores passa a ter um operador, ela perde $50 \%$ de seu pessoal. Este estudo foi decorrente de uma redução de onze para oito operadores por turno. 
10. As refinarias têm um funcionamento contínuo e, portanto, têm equipes de trabalhadores se revezando dia e noite, segundo diferentes esquemas de turnos, com duração de seis ou oito horas e, no mínimo cinco equipes (a cada dia, quatro trabalhando e uma de folga).

11. Alguns anos depois, soubemos que alguns operadores tinham sido punidos por terem levado a questão a público, com transferências para regiões distantes e com mudanças de funções.

12. Como não há interrupção no processo, é necessário que o número de operadores seja maior do que o número necessário para operar cada unidade, a fim de poder cobrir ausências eventuais e férias. Portanto, existem dois números a serem considerados no dimensionamento de pessoal: o chamado "número (ou quadro) mínimo" e o "número (ou efetivo) total", o qual, por definição, é sempre maior que o mínimio. Quando não se alcançava o "número mínimo", operadores do turno anterior deveriam "dobrar" turno, ou seja, permanecer trabalhando por mais uma jornada de trabalho. Estes conceitos estavam no coração das discussões sobre dimensionamento de pessoal.

13. "O trabalho dos petroleiros: perigoso, complexo contínuo e coletivo" foi o título de um livro que escrevemos, posteriormente, com Aparecida Mari Iguti, sobre o assunto (Ferreira \& Iguti, 1996).

14. Neste caso, os "engenheiros" eram os chefes operacionais das unidades de processo.

15. Nos dois casos, significa considerar a empresa como um corpo humano, a ser modelado pelos atuais padrões de beleza: juventude, magreza e flexibilidade.

16. “O verbo to downsize é um termo técnico que vem da indústria automobilística, onde designa a diminuição do tamanho dos veículos. Foi em 1982 que começou sua aplicação aos empregados mais que aos produtos de uma firma. Desde então, os gerentes de recursos humanos inovaram um vasto léxico visando «adoçar» e mascarar semioticamente a supressão de empregos. Nos Estados Unidos atuais, principalmente nas grandes companhias, um trabalhador não é mais demitido, posto na rua: ele é «separado», «desselecionado», «transicionado» ou «reduzido», «não realocado», «desprogramado» ou «não renovado». Quanto à empresa, ela se contenta em proceder a uma «recentragem do mix de qualificações», a uma «correção do desequilíbrio de mão de obra» ou ainda a uma «eliminação de redundâncias». Muitas outras palavras dificilmente traduzíveis, como decruited, excessed, ou surplussed exprimem bem esta idéia que os empregados se tornaram uma carga excedente, um peso morto, um fardo inútil, enfim, uma tara de cuja firma tem não só o direito mas o dever de se desfazer rapidamente" (Wacquant,1996, p70,tradução livre).

17. Esta etapa está prevista no método que inspirou este estudo: a Análise Ergonômica do Trabalho (AET).

18. Ao longo de todos estes anos, a busca de respostas para estas questões e de teorias para respaldá-las constitui o principal esforço de Dejours. Como ele diz, a psicodinâmica do trabalho "é uma disciplina clínica [...] mas também uma disciplina teórica, que se esforça para inscrever os resultados da investigação clínica sobre a relação no trabalho em uma teoria do sujeito, que leva em conta a psicanálise e a teoria social."(Dejours, 2001, p.1,tradução livre).

19. O tema do reconhecimento mereceria um estudo mais aprofundado que ultrapassa as possibilidades deste artigo. No entanto, gostaria de lembrar alguns resultados de uma breve pesquisa que realizei ao escrever o presente texto. Em 2007, a revista Travailler publicou um dossier especial (sob os cuidados de C. Dejours), sobre o tema do reconhecimento, com um artigo do francês Emmanuel Renault, Reconnaissance et travail, e de três pesquisadores todos eles do Instituto de Pesquisa Social da Universidade de Frankfurt, inclusive de seu diretor atual Axel Honneth. $\mathrm{O}$ artigo de Honneth, Travail et agir instrumental. À propos des problèmes catégoriels d'une théorie critique de la société é a tradução francesa de um artigo publicado em alemão em 1980. Kocyba escreveu Reconnaissance, subjectivisation, singularité e Voswinkel escreveu L'admiration sans appréciation. Les paradoxes de la double reconnaissance du travail subjectivisé. Honneth é o autor de Luta por reconhecimento: a gramática moral dos conflitos sociais, tradução brasileira de uma obra publicada em alemão em 1992 e fruto de sua tese de livre 
docência, onde ele "tenta desenvolver os fundamentos de uma teoria social de teor normativo partindo do modelo conceitual hegeliano de uma "luta por reconhecimento" (Honneth, 2009). O livro de Ricoeur, traduzido no Brasil em 2006, se chama Percurso do reconhecimento. Em um outro texto que tem o sugestivo título de "Tornar- se capaz, ser reconhecido" (2005, tradução livre) onde brinca com os dois polos da identidade pessoal de cada um: as capacidades que a pessoa sabe possuir e a necessidade que sente de que outros as reconheçam, diz ele: "eu me identifico pelas minhas capacidades, pelo que sei fazer"

20. Nos Estados Unidos, um estudo revelou o número de empregos nas indústrias de petróleo e gás diminuiu drasticamente entre 1982 e 1999, passando de um nível máximo de 1.650 .000 empregados a aproximadamente 640.000. Entre 1988 e 2000, as empresas de petróleo dos Estados unidos despediam em média 5,25\% de seus empregados a cada ano. (Gas Daily, Arlington, Virginia, 2 de junho de 2000).

\section{RESUMOS}

O texto pretende discutir alguns resultados de um estudo desenvolvido pela autora há vinte anos, à luz do conceito de "reconhecimento do trabalho" tal qual a psicodinâmica do trabalho o apresenta. $O$ estudo foi o primeiro de uma série de outros que se seguiram nos quinze anos posteriores, sempre relacionados à luta de trabalhadores petroleiros brasileiros contra a política de "enxugamento de pessoal", versão brasileira do downsizing, aplicada pela direção da empresa nos anos 90, na esteira das políticas chamadas de reestruturação produtiva que invadiram as empresas brasileiras e mundiais, particularmente, o setor de petróleo.

El texto busca analizar algunos resultados de un estudio desarrollado por la autora hace veinte años, a la luz del concepto de "reconocimiento del trabajo", tal cual lo presenta la Psicodinámica del Trabajo. La investigación fue la primera de una serie de otros estudios realizados los quince años siguientes, siempre concernientes a la lucha de trabajadores petroleros brasileños contra la política de "recorte de personal" (enxugamento de pessoal, según la traducción brasileña de downsizing), aplicada por la dirección de la empresa en los años 90, en el marco de las políticas llamadas de reestructuración productiva, que invadieron las empresas brasileñas y mundiales, de modo particular el sector petrolero.

Le texte cherche à discuter quelques résultats d'une étude développée par l'auteur il y a vingt ans, à la lumière du concept de "reconnaissance au travail", tel que la psychodynamique du travail le conçoit. Cette étude a été la première d'une série qui s'est étendue au cours des quinze années suivantes, toujours en rapport avec la lutte des travailleurs pétroliers brésiliens contre la politique de "enxugamento de pessoal", expression brésilienne qui correspond au dégraissage d'effectifs (downsizing). Cette politique a été appliquée par la direction de l'entreprise au cours des années 1990, dans le contexte des politiques de restructuration productive qui ont envahi les entreprises brésiliennes et mondiales et qui ont atteint, particulièrement, le secteur pétrolier.

The text presents the results of a study developed 20 years ago by the author in light of the concept of "recognition of work" according to the psychodynamics of work. This study was the first of a series of other works that followed in the next 15 years related to the struggle of petroleum workers against the "enxugamento de pessoal" policy, the Brazilian version of downsizing. A policy applied in the 1990s by the company management in the wake of a policy 
known as productive restructuring which was widely adopted by Brazilian and international firms and particularly by the petroleum sector.

\section{ÍNDICE}

Palabras claves: trabajo, petróleo, recorte de personal, reconocimiento del trabajo, psicodinámica del trabajo

Keywords: work, petroleum, reduction of permanent staff, recognition of work, psychodynamics of work

Palavras-chave: trabalho, petróleo, redução de efetivos, reconhecimento do trabalho, psicodinâmica do trabalho

Mots-clés: travail, pétrole, dégraissage d'effectifs, reconnaissance du travail, psychodynamique du travail

\section{AUTOR}

\section{LEDA LEAL FERREIRA}

Pesquisadora do Serviço de Ergonomia, Fundacentro - Ministério do Trabalho e Emprego, Rua Capote Valente,710, São Paulo, SP-Brasil

leda@fundacentro.gov.br

Manuscrito recebido em : Dezembro/2010

Aceite após peritagem em : Maio/2011 